\title{
Detailed Barkhausen noise and microscopy characterization of Jominy end-quench test sample of CF53 steel
}

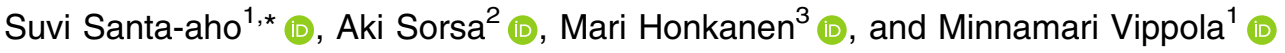 \\ ${ }^{1}$ Faculty of Engineering and Natural Sciences, Tampere University, P.O. Box 589, 33014 Tampere, Finland \\ ${ }^{2}$ Faculty of Technology, Control Engineering, University of Oulu, P.O. Box 4300, 90014 Oulu, Finland \\ ${ }^{3}$ Tampere Microscopy Center, Tampere University, P.O. Box 692, 33014 Tampere, Finland
}

Received: 4 September 2019

Accepted: 6 December 2019

Published online:

12 December 2019

(C) The Author(s) 2019

\begin{abstract}
Jominy end-quench test samples from CF53 were used for studying the relationship of microstructural changes with the magnetic Barkhausen noise (BN) response. As the Barkhausen noise method is sensitive to both stress and microstructural state, it can be applied for material characterization. This study presents observations from BN measurements with different sensors and from different locations (as-quenched and ground) on the sample surface. Detailed microstructural characterization with a scanning electron microscope and a transmission electron microscope was carried out to correlate the $\mathrm{BN}$ responses with the microstructural features. In addition, residual stresses were measured by X-ray diffraction. The results indicate that the ground surface displayed mainly the effect of the grinding compressive stress state, while the as-quenched surface had variations due to higher microstructure sensitivity. An important finding of the results was that the sensitivity of $\mathrm{BN}$ to different surface conditions varied: The BN response in the ground area was mainly generated by both the residual stress and the microstructural effect, whereas for the as-quenched surface the microstructural effect was more evident.
\end{abstract}

\section{Introduction}

\section{Jominy end-quench test in general}

The Jominy end-quench test is a standardized hardenability test for steels. The SFS-EN ISO 642 standard [1] describes the methodology to machine Jominy bars and to carry out heat treatment. Commonly, Jominy tests are used to predict the depth of hardening and the so-called Jominy curves are utilized for characterizing the steel grade. Using Jominy tests, a comparison can be made of the hardenability, i.e., the ability to form martensite on the quenching of different steel grades.

Address correspondence to E-mail: suvi.santa-aho@tuni.fi 
Hardenability is greatly affected by the chemical composition of the steel grade and the austenite grain size $[2,3]$. The maximum hardness ( $100 \%$ martensite) depends mainly on the carbon content up to the level of $0.5 \mathrm{wt} \%$, after which any increase has a minor effect [2]. Adding nickel, manganese, chromium or molybdenum, for example, enhances the stability of austenite and produces deep hardening by changing the time-temperature-transformation curves [3]. A similar effect can be observed when the austenite grain size is increased [2, 3].

According to standard SFS-EN ISO 642 [1], the Jominy sample is first austenitized in a furnace and then quenched using a water nozzle. During the subsequent quenching, the microstructure and hardness are affected by the rate of the temperature change. In the Jominy end-quench test, the rate of cooling is greatest at zero distance from the quenched end and the cooling rate decreases as the distance from the quenched end increases. The outcome of the Jominy test is verified by means of destructive hardness testing. A shallow layer (approximately $0.5 \mathrm{~mm}$ ) is ground off the longitudinal as-quenched surface, and hardness measurements are taken on this ground area. The hardness values as a function of distance reflect the differences in the cooling rate. The highest hardness values are at the quenched end, and progressively, lower hardness values are located along the sample.

\section{$\mathrm{BN}$ as a characterization tool}

Magnetic Barkhausen noise (BN) is a versatile tool used in the nondestructive testing field. The Barkhausen noise response has been proved to be sensitive to both the stress and the microstructural state of ferromagnetic material [4]. Therefore, besides the common online quality control where the method is widely applied, the BN method has also been utilized as a tool for material characterization. As Nakah [5] concluded in his review, the three major areas of $\mathrm{BN}$ research are residual stresses, microhardness and microstructure and how they correspond to $\mathrm{BN}$ features.

Several studies have been carried out to determine the $\mathrm{BN}$ response of hardened material when it is treated in such a way that both the hardness and the residual stresses are changed (tempering-induced microhardness variation studies by, e.g., [6, 7]). The $\mathrm{BN}$ method has also been used to determine different phases (including decarburization) or microstructures and their effect on $\mathrm{BN}$, e.g., in [8].

BN is affected by many different variables, but often in practical studies hardness and the microstructural state are combined to represent the same phenomenon. The microstructural state, however, determines the magnetic domain configuration of the phase and the pinning site distribution from the magnetic point of view. In addition, microstructural features such as grain boundaries are interfaces to the magnetic domain wall motion.

Hardness, on the other hand, is a physical property that has been generally used to explain the BN responses when the exact microstructure is not described. Although it is a material property, it can be said that hardness is created by the dislocation network and dislocations can be referred to as onedimensional linear defects. Therefore, it is worth bearing in mind the difference between microstructure and hardness and the fact that hardness is one mechanical property that is used to characterize the material. For example, two different samples may have the same hardness, but different microstructures, due to different heat treatments. In addition, as Franco et al. [9] pointed out, domain walls are threedimensional. Therefore, certain defects may pin a dislocation, but not a domain wall and certain other defects may pin both [9].

Martensite is known to be hard due to many crystalline defects that stop both dislocations and domain walls [9]. A pearlite structure consisting of ferrite and cementite is much softer in terms of hardness compared to martensite, but several authors $[8,10,11]$ have shown that pearlite colonies have a strong effect on domain wall pinning. Domain wall pinning is known to slow down the velocity of a moving domain wall. Therefore, an increased magnetic field is required to overcome these obstacles. When the domain walls are released abruptly from pinning sites, a voltage pulse is created. The pinning sites may have different pinning power, and the density of the pinning sites will affect the response.

For example, Lo et al. [10] studied pearlite spacing and its effect on BN. They [10] noticed that decreased spacing of the pearlite structure (increased cementite volume) caused stronger pinning, and thus, the BN signal decreased. However, Clapham et al. [11] stated earlier that interlamellar spacing had no significant effect on signal pulse height distribution. 


\section{Jominy and BN studies}

Some studies have been carried out to determine the BN response from different steel grades using the Jominy end-quench test. Franco et al. [9, 12] studied AISI (SAE) 4140, 6150 and 5160 structural steels for Jominy tests in their two articles quantifying the hardness of the Jominy bar using $\mathrm{BN}$ instead of destructive hardness measurements. The studies of Trillon et al. [13] had the same objective.

In the studies by Franco et al. [9, 12], the measurement surface for the $\mathrm{BN}$ measurements was the inner longitudinal surface, and therefore, the Jominy samples were cut into pieces and polished for taking measurements with a laboratory-made Barktech device. Franco et al. [9, 12] justified using the center as the measurement area owing to the less heterogeneous cooling rate there compared to the surface. The measurements were taken with constant measurement parameters, i.e., $0.8 \mathrm{~A}$ amplitude and 5, 10 and $20 \mathrm{~Hz}$ frequencies along the sample length.

Several BN parameters were studied in correlation with the distance from the quenched end. In Franco's study [12], the root-mean-square (RMS) value of BN showed an increasing trend as the distance from the quenched end increased to $16\left(1 / 16^{\prime \prime}\right)$ in AISI 4140 and to $18\left(1 / 16^{\prime \prime}\right)$ in AISI 5160 . Beyond these distances, the RMS decreased even though the hardness value was saturated to a level of approximately 350 HV. A similar drop in the RMS value was noticed in the studies of Padovese et al. [14] with AISI 4140.

In [9], the decrease in RMS at the other end was smaller with AISI 4140, but still visible. In contrast, the reduction was more profound with AISI 6150 and it was more visible at the lowest frequency, $5 \mathrm{~Hz}$, as well. In [9], the BN profile peak height displayed a similar trend to RMS, while the BN profile peak position value fell as the distance from the quenched end increased. However, these studies [9, 12] did not contain any residual stress measurements from the polished surface to confirm the stress state.

Trillon et al. [13] studied API carbon steel grade AISI 8650 pipe material using the Jominy hardenability test. They found that the BN peak position captured with a Microscan 600 device had linear correlation (in a certain hardness region: 33-47 HRC) with the Rockwell hardness that was measured from the Jominy test pieces. With low hardness below 33 HRC, the hardness peak position was saturated, and at the high-hardness end, i.e., greater than $47 \mathrm{HRC}$, the hardness peak position correlation was exponential. The carbon steel grade had a hardness of over 30 HRC throughout the sample. The authors [13] concluded that they could utilize the peak position value as an alternative method for evaluating the hardness of the steel pipe nondestructively. The peak position was negative when the hardness decreased below 41 HRC [13]; however, no detailed information about the measurements was given in the article.

Prabhu Gaunkar et al. [15] used high-hardenability 18CrNiMo7-6 low-alloy steel to study the relationship of different microstructures to BN signals. They [15] illustrated the changes in magnetic susceptibility with different microstructures in the Jominy bar. In addition, they demonstrated the simulation of $\mathrm{BN}$ profiles from locations with different microstructures. The measurements were taken with $10 \mathrm{~V}$ voltage and a magnetization frequency of $30 \mathrm{~Hz}$. The measurements confirmed the $\mathrm{BN}$ profile simulation results: The amplitude and position were dependent on the microstructure. In the $50 \%$ martensite region, two different peaks appeared, indicating that two magnetically different phases were present. The signal amplitude was higher for the martensite structure and lower for the location corresponding to the ferrite-pearlite combination.

\section{Problem statement and the aim of the paper}

Usually the Barkhausen noise method is used in qualitative quality control to determine changes in the regularly utilized RMS value of the voltage signal. Large variations in microstructure as in the Jominy end-quench samples are not normally present in the industrial use of $\mathrm{BN}$, because the structures are assumed to be homogeneous and the variations in the BN signal are determined in the quality control tasks. Therefore, the measurement is straightforward: The main aim is to compare the RMS value to a certain predetermined threshold value and evaluate the success of the grinding operation on that basis. The utilization of Barkhausen noise for characterization is different because the outcome of the measurement depends on many different issues as shown in "Results" section. (The signal varies due to surface characteristics, ground and as-quenched, and due to different microstructures and sensors.)

This study analyzes Jominy end-quench samples made of CF53 with $\mathrm{BN}$ and material characterization tools. The aim of this paper is to link the threshold 
RMS values to material properties to better understand the BN measurement result. Also, we aim to explain the opposite trend of the RMS value in the low hardness end of the bar, which was not clearly explained in earlier papers $[9,12,14]$.

\section{Experimental section and methods}

\section{Materials and methods}

Low-alloy CF53 steel material was used to prepare three Jominy samples (A, B and C) according to standard ISO 642 [1]. Samples A and B were used for measurements, and sample $\mathrm{C}$ was cut and used for microstructural evaluation. The chemical composition of the sample material is presented in Table 1.

The geometry of the Jominy sample is presented in Fig. 1. The diameter was $25 \mathrm{~mm}$ and the length $100 \mathrm{~mm}$. The samples were austenitized with a hold time of $30 \mathrm{~min}$ prior to the water quench with a water nozzle. A Nabertherm $\mathrm{N} 41 / \mathrm{H}$ heat treatment chamber furnace was used in normal atmosphere (air) with a carbon bed where the sample was covered with carbon powder to avoid decarburization. The quenched end was cooled by water quenching, and the other end was air-cooled.

An Emcotest M4C-250 hardness tester was used for surface hardness measurements with Rockwell $C$ from the ground areas (A, B and C) on opposite sides of the samples shown in Fig. 1. The grinding was done according to standard [1] with surface grinding equipment using a coolant. Microhardness measurements were taken with a Matsuzawa hardness tester with a load of $5 \mathrm{~g}$. The Barkhausen noise and surface $X$-ray diffraction residual stress measurements were taken from the ground area shown by the white line (Fig. 1) and from the as-quenched area shown by the red line. Nondestructive Barkhausen noise measurements were taken using a Rollscan 300 BN analyzer manufactured by Stresstech Oy (Finland). The commercial sensor used for the as-quenched area was

Table 1 Chemical composition of CF53 material

\begin{tabular}{llllllll}
\hline & $\mathrm{C}$ & $\mathrm{Si}$ & $\mathrm{Mn}$ & $\mathrm{P}$ & $\mathrm{S}$ & $\mathrm{Cr}$ & $\mathrm{Al}$ \\
\hline Min \% & 0.52 & 0.15 & 0.4 & - & 0.015 & 0.10 & 0.015 \\
Max \% & 0.56 & 0.35 & 0.7 & 0.025 & 0.035 & 0.23 & 0.040 \\
\hline
\end{tabular}

S5857 for the tangential direction of the Jominy sample. The sensor surface was curved to fit the round shape of the sample bar. A smaller commercial sensor, S8276N, was used for the tangential measurement direction of the ground areas. The measurements with sensor 55857 were taken with a magnetizing frequency of $125 \mathrm{~Hz}$ and magnetizing voltage of $5 \mathrm{Vpp}$ (voltage from peak to peak). An analyzing frequency range of $70-200 \mathrm{kHz}$ was utilized. The measurements with sensor $\mathrm{S} 8276 \mathrm{~N}$ were taken with a magnetizing frequency of $250 \mathrm{~Hz}$ and magnetizing voltage of $1.5 \mathrm{Vpp}$ (voltage from peak to peak). An analyzing frequency range of 70-200 kHz was utilized. Microscan software was used to record raw BN data, and certain features (the RMS value of the $\mathrm{BN}$ amplitude and peak position) were chosen for the analysis. Because two sensors of different sizes were used, the measurement frequency and voltage used for each sensor were optimized by means of magnetizing sweeps in order to gain suitable signal level. The measurements were repeated three times, and the mean was used in the analysis. The standard deviation of the mean was $1 \%$. And thus, the expanded uncertainty of the measurement is $2 \%(k=2)$.

The surface residual stress (RS) and full width at half maximum (FWHM) of the diffraction peak values were examined from the same locations as in the BN measurements using an XStress 3000 X-ray diffractometer (XRD), manufactured by Stresstech Oy (Finland). RS measurements were taken using $\mathrm{CrK} \alpha$ radiation and the modified Chi-squared method [16]. The current used was $6.7 \mathrm{~mA}$ and voltage $30 \mathrm{kV}$. The XRD residual stress measures type I (macro-) and II (micro-) stresses where the length scale is from grains to a large quantity of grains. Type III stress affects the full width at half maximum (FWHM) of the diffraction peak as they are influenced by dislocations, for example [17].

The microstructures of the $C$ sample were characterized using a Philips XL30 scanning electron microscope (SEM). The cross-sectional longitudinal image plane for the SEM images is shown by the blue area in Fig. 1. The microstructures were analyzed from etched metallographic cross-sectional samples. Samples were prepared by grinding with 320-4000 $\mathrm{SiC}$ papers and then by polishing with a $3 \mu \mathrm{m}$ diamond suspension. The etching procedure was performed with $4 \%$ Nital. The SEM images were processed with ImageJ software to calculate the ferrite fraction from the pearlite-ferrite structures. First, 
Figure 1 Schematic figure showing the measurement locations (red and white lines) for Barkhausen noise and X-ray diffraction methods from different sides of the sample. Numbers 1 and 2 indicate the surface hardness measurement areas that were ground.
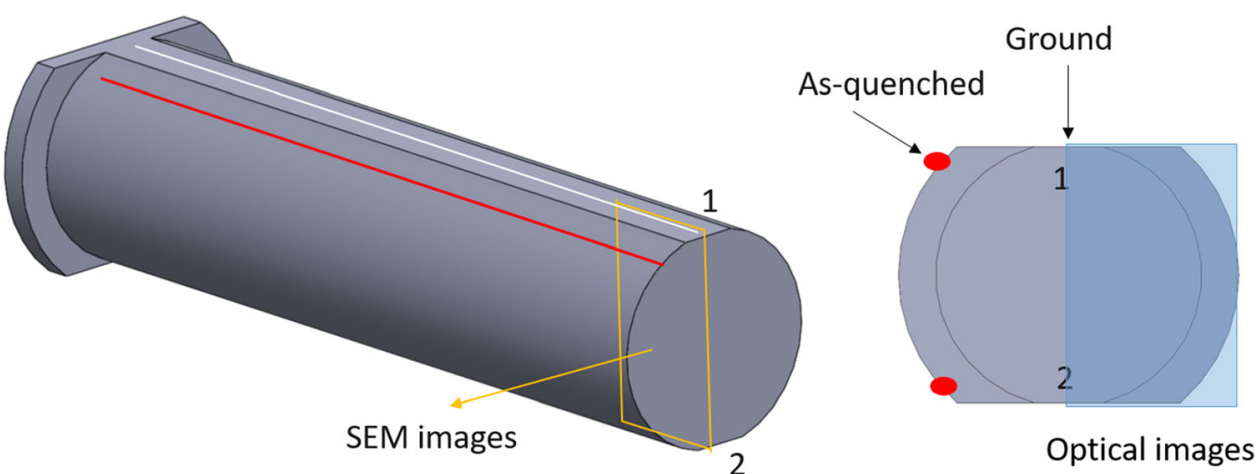

the SEM images were converted into grayscale. Next, image thresholding was utilized to calculate the area of the ferrite region. Optical microscopy was carried out in a different direction than the SEM shown in Fig. 1, using a Nikon Eclipse MA 100 optical microscope.

The magnetic domains in the Jominy samples were imaged by a Jeol F200 transmission electron microscope (TEM). The domain walls were observed in Lorentz mode, i.e., low-magnification mode with an objective mini-lens, to avoid an external magnetic field on the sample position. Lorentz microscopy has two different modes: Foucault and Fresnel, and here, the latter was used. Adjoining magnetic domains cause different deflections for incident electrons producing a contrast to the TEM image between the domains. In the Fresnel mode, a defocused image reveals the position of domain walls and domain boundaries are observed as light or dark lines, which is useful for identifying the geometry of magnetic domains. TEM samples were taken from areas $1.5 \mathrm{~mm}$ from the quenched end (martensite) and from $70 \mathrm{~mm}$ from the quenched end (mixed ferrite-pearlite). Samples for the TEM studies were prepared with a Struers TenuPol-5 twin-jet electrolytical polishing system using a solution of nitric acid in methanol (1:2) at $-50{ }^{\circ} \mathrm{C}$. Pre-thinning before electropolishing was carried out mechanically with 4000 $\mathrm{SiC}$ papers to a thickness of $0.1 \mathrm{~mm}$, and then, 3-mmdiameter disks were cut with a punch.

\section{Results}

\section{Hardness}

The surface hardness along the different measurement lines 1 and 2 from Jominy bars A, B and C is presented in Fig. 2a, b. The ground measurement location 1 of Jominy bars A and C had some deviations in the quenched end hardness as shown in Fig. 2a, and the decreased hardness was observed only in the quenched end of one side of the samples in $\mathrm{A}$ and $\mathrm{C}$. This may be the result of non-uniform cooling, i.e., if one side of the bar enters the water first and cools more rapidly producing a higher cooling rate and consequently higher hardness. In addition, the homogeneity in the distribution of the alloying elements may cause deviation [3].

\section{Microstructural evaluation}

\section{SEM results}

The SEM micrographs (Fig. 3a-h) were taken from sample $C$ with 1.5, 3, 5, 11, 20, 30, 50 and $65 \mathrm{~mm}$ from the quenched end, respectively. Microstructural observation and surface hardness measurements along the ground sample surface showed a gradual change in the microstructure from martensite (Fig. 3a) to mixture of martensite and bainite (Fig. 3b), with the dark areas ascribed to martensite in a mixture of pearlite and ferrite (Fig. 3c-f). It can be seen that the pearlite lamella spacing varies randomly, as shown in Fig. 3h). This steel grade, CF53, had very low hardenability as seen from the hardness curves (Fig. 2) and micrographs (Fig. 3). As the hardness decreased, the amount of ferrite in the structure increased in the mixed microstructure as the evolution of the microstructure proceeded. The appearance of ferrite and pearlite is known to correspond to a large reduction in hardness [3].

The pearlite structure containing the white cementite lamellas and black ferrite regions was also seen to change, as shown in Fig. 3. The maximum cementite lamella distance (interlamellar spacing) in the pearlite structure was counted from random 
Figure 2 Surface hardness from two different measurement lines $\mathbf{a} 1$ and $\mathbf{b} 2$ along Jominy samples A, B and $\mathrm{C}$.

Figure 3 SEM images of Jominy sample $\mathrm{C}$ at different distances from the quenched end: a $1.5 \mathrm{~mm}, \mathbf{b} 3 \mathrm{~mm}$, c $5 \mathrm{~mm}, \mathbf{d ~} 11 \mathrm{~mm}$, e $20 \mathrm{~mm}$, f $30 \mathrm{~mm}, \mathrm{~g} 50 \mathrm{~mm}$ and h $65 \mathrm{~mm}$.
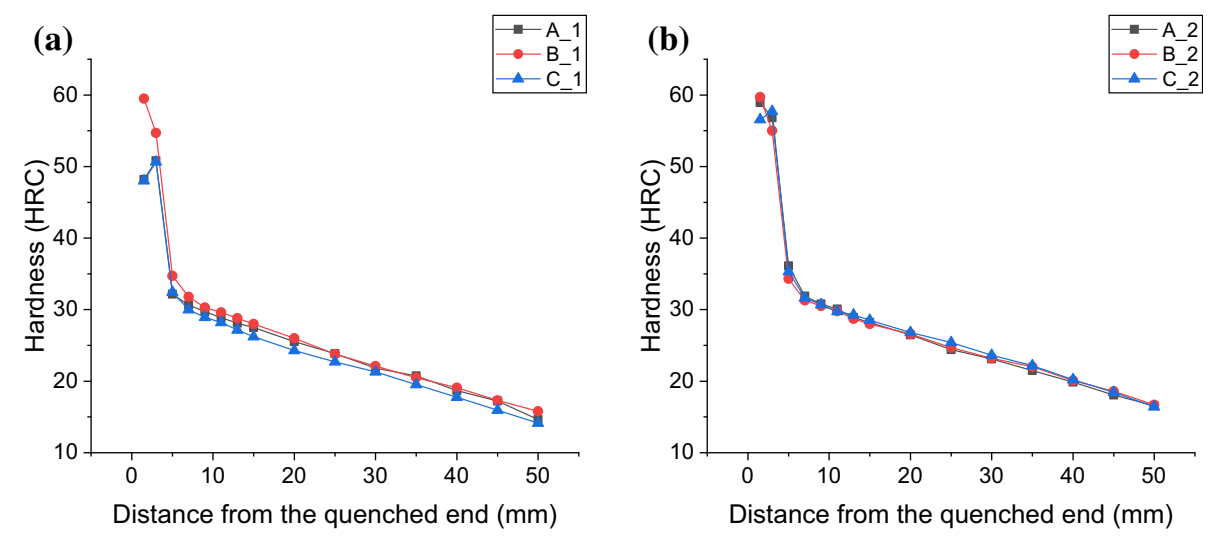
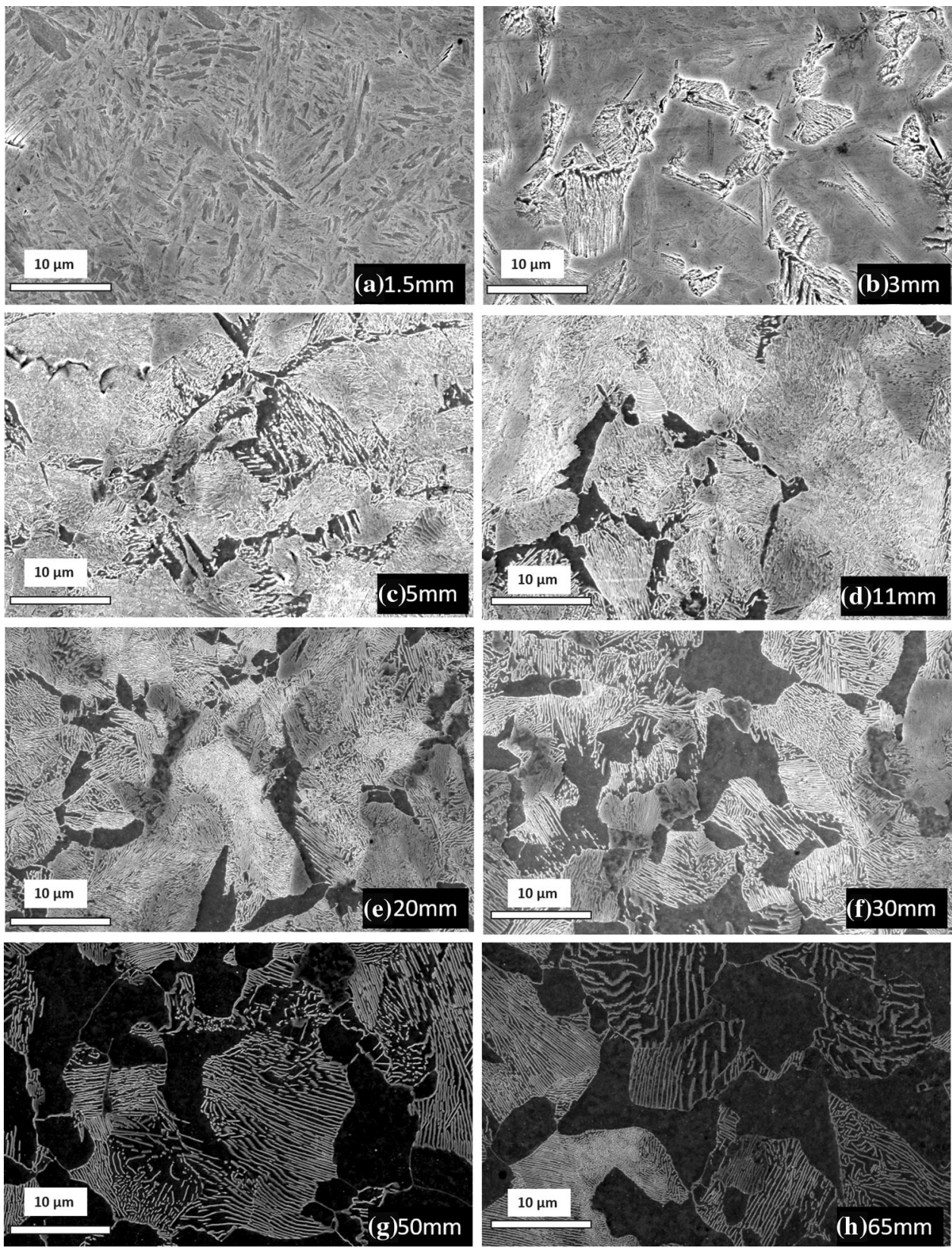
pearlite colonies in the micrographs with a higher magnification and is presented in Fig. 4. The number of cementite lamellas for the same length in the pearlite structure decreased in the structure as the distance from the quenched end increased. With a constant cooling rate, the interlamellar spacing in pearlite is said to be constant [18]. The effect of a slower cooling rate at the non-quenched end can be seen in changes in the interlamellar spacing [18].

\section{ImageJ results from SEM}

The ferrite fraction results obtained from the SEM images (Fig. 3) with ImageJ software are presented in Fig. 5. The ferrite fraction increases as the distance from the quenched end increases. This result corresponds well with the hardness measurements of the Jominy sample (Fig. 2).

\section{TEM results}

Figure 6a-d shows the detailed microstructure captured by TEM from sample $C$ martensite (quenched end) and mixed ferrite-pearlite $70 \mathrm{~mm}$ from the quenched end. The microstructure is captured using normal TEM mode, while the Fresnel mode was utilized to capture the magnetic domain walls in the samples. In the Fresnel mode, a defocused image reveals the position of domain walls and domain boundaries are observed as light or dark lines in overfocus (Fig. 6b, d) or underfocus (Fig. 6a, c). Some

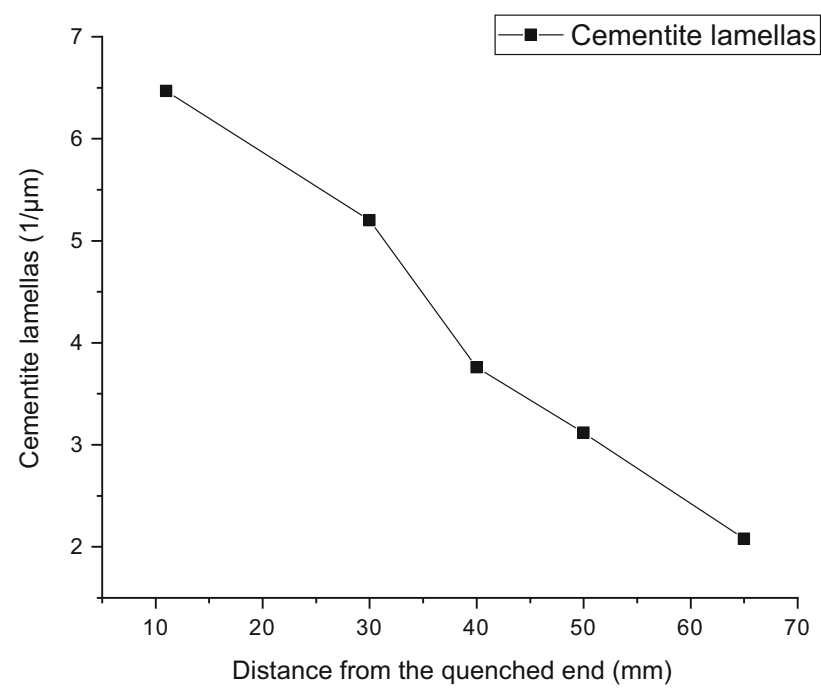

Figure 4 Interlamellar spacing of the cementite in the pearlite structure.

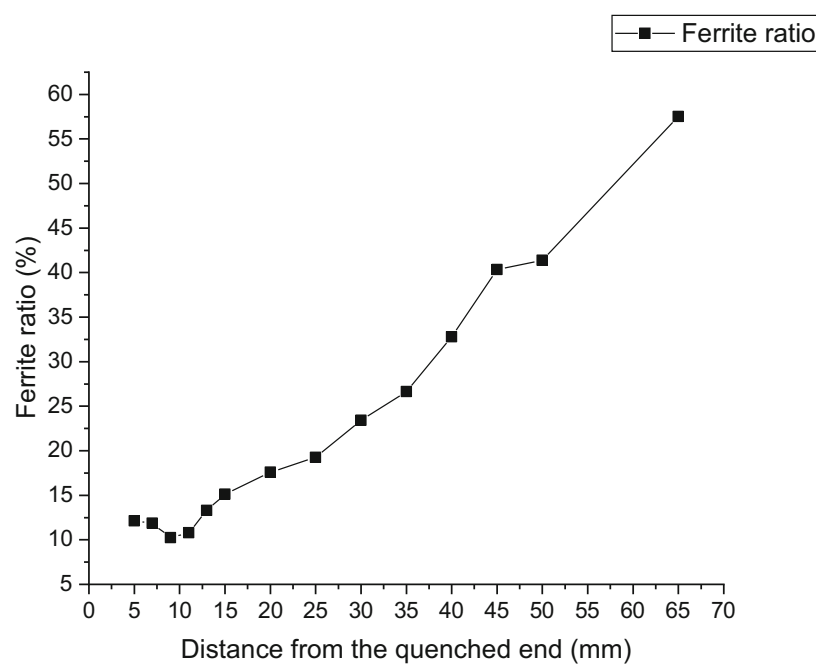

Figure 5 Ferrite ratio calculated with ImageJ software (sample C).

of the magnetic domain walls are depicted in Fig. 6 with blue arrows. Figure 6 shows, from this small region of the TEM sample, that the domain structure is smaller in the martensite phase than in the ferritepearlite. However, the domain structure has both small and large areas in the ferrite-pearlite.

\section{Optical microscopy}

Heat treatment without inert gas may cause formation of a decarburized layer consisting of ferrite. Decarburization is generated due to the reaction of carbon and oxygen at high temperatures. In this study, excess decarburization was prevented by using a carbon bed on which the sample was placed in the furnace. However, to determine the decarburization phenomena, samples were prepared from another section to determine whether the samples contained a decarburized layer. Optical micrographs were taken from another cross section, shown in Fig. 1. Based on a visual inspection along the bar, the decarburization layer was visible in the region where the mixed microstructure (pearlite-ferrite) was observed from $40 \mathrm{~mm}$ from the quenched end to the end of the bar. A decarburization layer, approximately 50-90 $\mu \mathrm{m}$ thick, was visible $40 \mathrm{~mm}$ from the quenched end, as shown in Fig. 7.

\section{Barkhausen noise results}

The Barkhausen noise measurements were taken with two sensors due to the geometrical issues. The 
Figure 6 Magnetic domain walls captured in TEM Fresnel mode a martensite

(underfocus), b martensite (overfocus), c ferrite-pearlite (underfocus), $\mathbf{d}$ ferrite-pearlite (overfocus). Blue arrows indicate the magnetic domain walls.
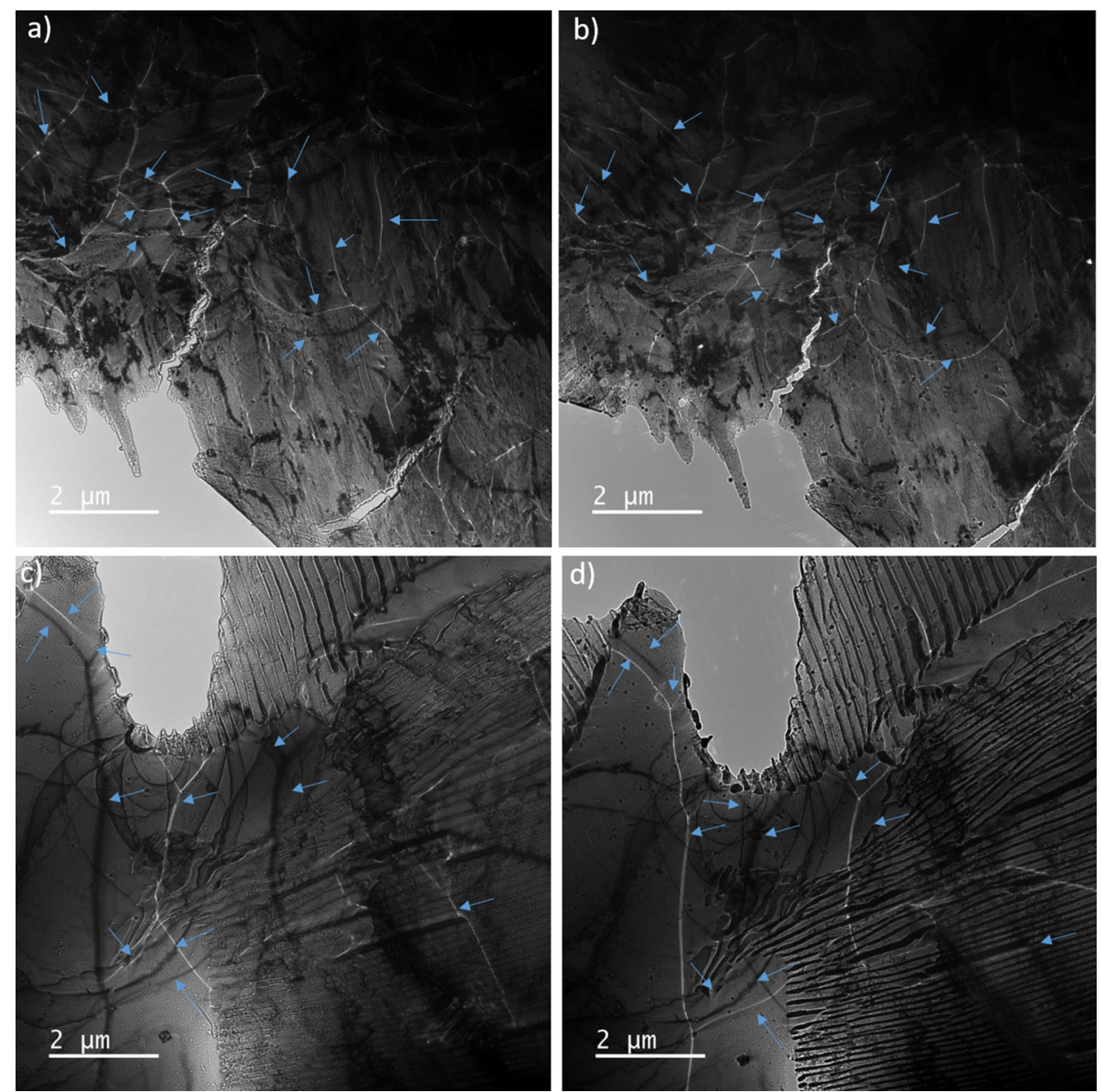

ground surface was measured with sensor S8276N in the tangential direction from the ground region where the hardness measurements were taken, and the as-quenched surface was measured from the position depicted in Fig. 1 with sensor S5857 in the tangential direction. The RMS increased as a function of distance from the quenched end to $55 \mathrm{~mm}$ from the quenched end and had a slight decrease in the location $70 \mathrm{~mm}$ from the quenched end, as presented in Fig. 8a for the ground surface, whereas in the asquenched surface, the RMS decreased as a function of the distance from the quenched end (Fig. 8b). The

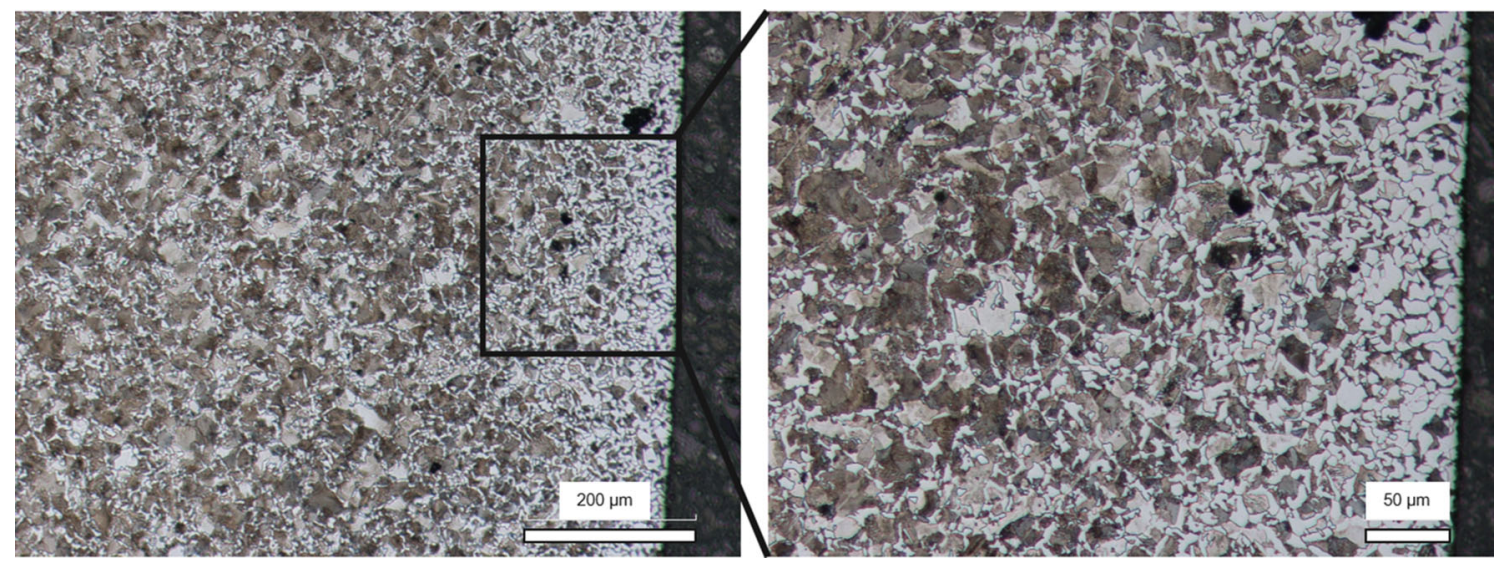

Figure 7 Decarburization layer on as-quenched surface at $40 \mathrm{~mm}$ from the quenched end (sample C). 
results from the ground surface showed more variation between samples $\mathrm{A}$ and $\mathrm{B}$ and measurement locations 1 and 2 .

Residual stresses were measured in the same direction as the BN measurement direction (tangential). It should be noted that XRD RS measurements utilize information on the diffraction peak shift caused by type I (macro-) and II (micro-) stresses, and that $\mathrm{BN}$ measurements are influenced by the internal stresses via magnetostriction phenomena [17]. The ground surface had compressive residual stresses along the measured line as illustrated in Fig. 9a. Near the quenched end, the compressive stresses were larger and showed a lot of deviation between the different samples and measurement locations. In contrast, in the as-quenched surface, 10 to $55 \mathrm{~mm}$ from the quenched end residual stresses were equal to zero. Near the quenched end, tensile residual stresses were present and, at the other end $(72 \mathrm{~mm})$, the residual stresses were compressive and showed a lot of variation (Fig. 9b).

Figure 10 presents the peak position value calculated using Microscan software. The peak position determines the location of the maximum $\mathrm{BN}$ events. The trend is decreasing as the hardness diminishes in the ground surface (Fig. 10a) and in the as-quenched surface (Fig. 10b) with the exception of the last measurement point, $70 \mathrm{~mm}$ from the quenched end. The difference is the scale: In the as-quenched condition, all the peak position values are negative which may be due to software issues.

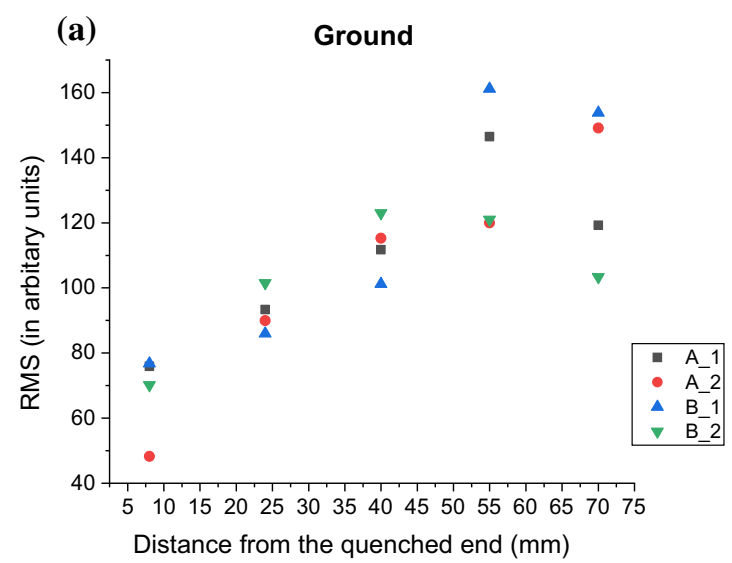

\section{Discussion}

Generally, the hardness and microstructure change along the Jominy bar according to composition, transformation temperature and cooling rates. As verified, the cooling rate is higher at the quenched end of the Jominy bar decreasing toward the other end. The BN features change along the bar as well. Depending on the sensitivity of a certain BN feature to material characteristics, different behavior may be observed for the BN features.

As stated in the introduction, some inconsistency had been observed in the $\mathrm{BN}$ versus hardness trend in some previous studies concerning Barkhausen noise measurements from Jominy samples. The general trend for the BN RMS value should increase with decreasing hardness, but in the studies of Padovese et al. [14], the opposite trend between RMS and hardness was observed for 4140 steel. As presented even earlier, Franco et al. [9] noted the same trend for two different materials: AISI 4140 and AISI 5160. The tendency was highly dependent on the steel material; AISI 4140 showed a dramatically opposite trend to AISI 5160. In addition, Padovese et al. [14] encountered this same tendency with SAE 4140 steel. However, the reason for the drop in RMS was not described in detail in the articles.

\section{Reproducibility of Jominy samples}

The separate Jominy end-quench samples were noted to have some variations in the hardness measurements (Fig. 2). The precision and reproducibility of the Jominy test were discussed in [2] where the results of nine different laboratories carrying out

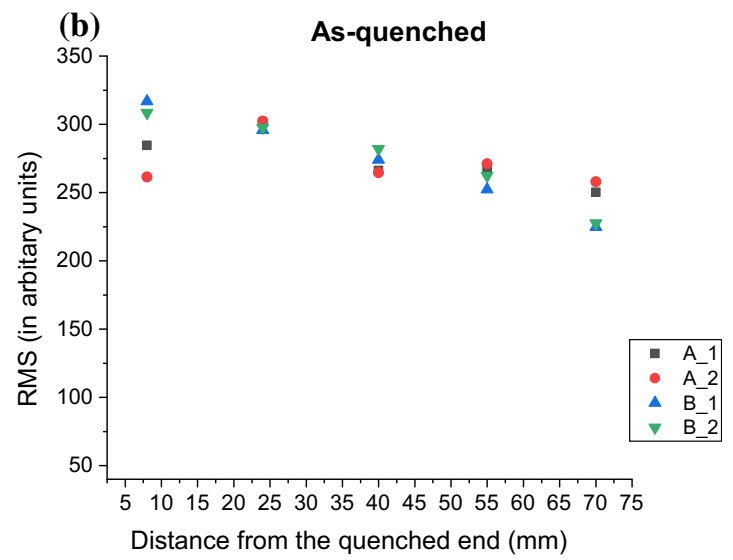

Figure 8 RMS results along the a ground line with sensor S8276N and $\mathbf{b}$ as-quenched surface with S5857. 
(a)

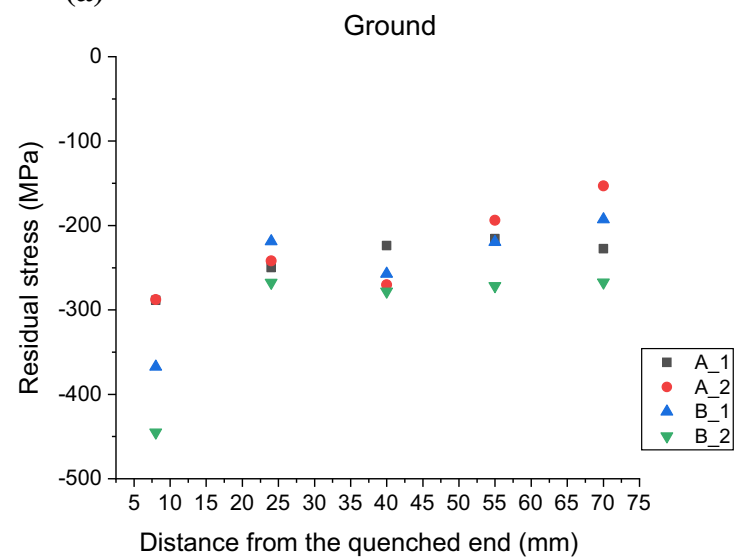

(b)

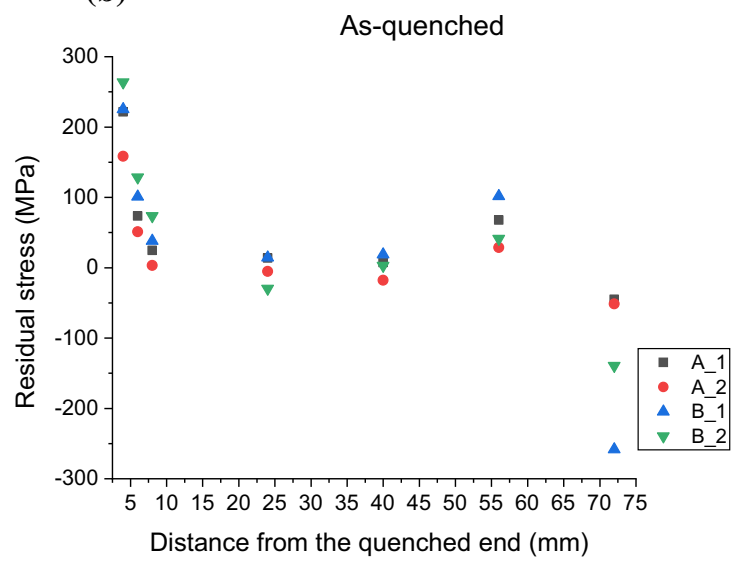

Figure 9 Residual stress results along the a ground line and $\mathbf{b}$ as-quenched surface to the tangential direction of the sample.

(a)

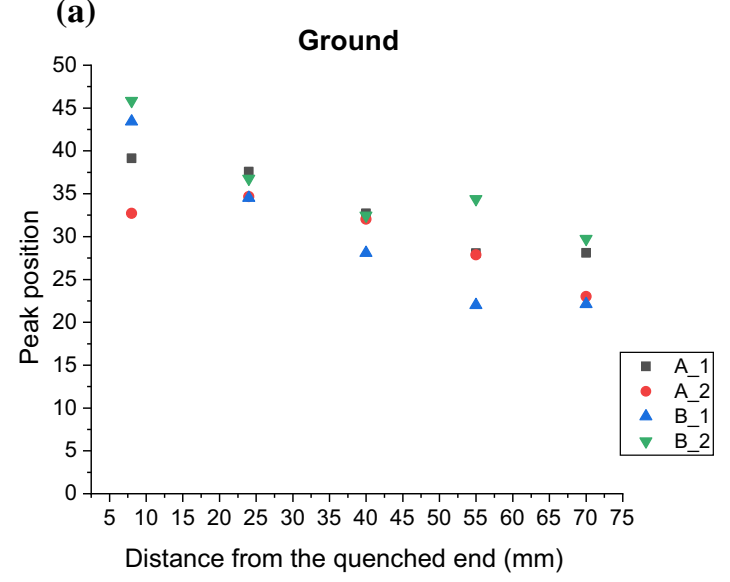

(b)

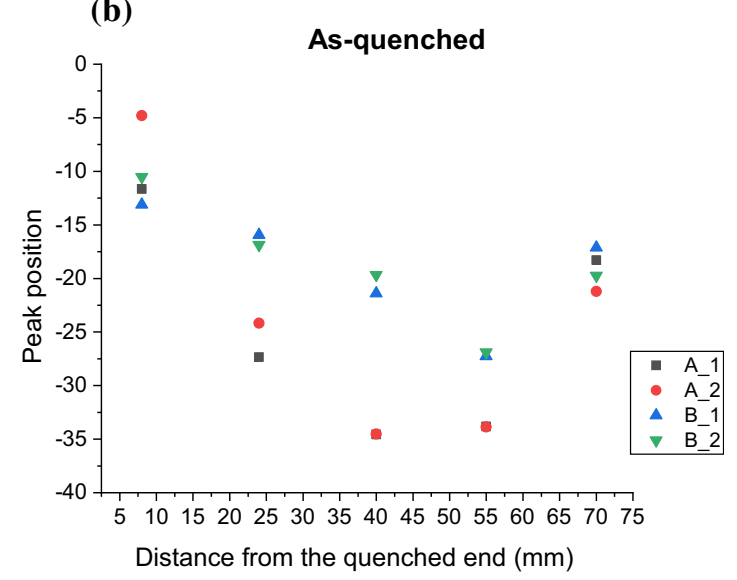

Figure 10 Peak position results along the a ground line with sensor S8276N and $\mathbf{b}$ as-quenched surface with S5857.

similar Jominy samples were compared. Kirkaldy [2] described the general difficulties in providing reproducible Jominy end-quench samples. The experimental reproducibility of hardness was \pm 6 HRC (in the steepest region of the hardness curve). Kirkaldy [2] also mentioned another study where it was observed that the precision of the Jominy test also reflected variations in melt shop practices that determine the inclusion content and ultimately affected the grain size. Both random and systematic errors were noticed in different process steps: sampling, heat treating, grinding and hardness testing (mainly in the case of device calibration). The cooling water temperature may vary as well as the height at which the water collides with the bar. The same was noticed in the Jominy end-quench samples in this study. All the Jominy bars were machined from a larger bar, and the same decreased hardness values on one side of the bar may be related to the initial microstructure and its variations along the machined bar.

The quenching of the Jominy sample is crucial. If the cooling water does not come directly in contact with the quenched end, this may cause uneven cooling rates and affect the microstructures produced. The microstructures may not be homogeneous. The cooling water temperature may vary as well as the height to which the water rises in the bar.

The BN measurement locations also varied in the earlier studies $[9,13]$. In most cases, the measurements were taken from the longitudinal centerline or multiple positions near the centerline [9]. In those cases, the effect of the decarburization layer can be eliminated. However, it was not clear whether the measured surface was only machined or polished afterward [9]. Due to the different known responses, 
two measurement locations were used in this study: the ground surface and the as-quenched surface. It was observed that these two locations exhibited different RMS trends (Fig. 8).

\section{Measurements from as-quenched surfaces}

As-quenched surfaces are rarely measured with $\mathrm{BN}$. Instead, the surfaces are machined, i.e., ground or shot-peened. During austenitization heat treatment, decarburization may occur, leading to the phenomenon where the carbon at the surface reacts with the oxygen in the surrounding atmosphere. The loss of carbon at the surface may lead to changes in the surface structure as several properties of the steel (for example, hardness and fatigue strength) are dependent on the carbon content. In addition, Hao et al. [19] pointed out that a fully decarburized layer has a higher relative permeability compared to pearlite, while a partially decarburized layer has a lower permeability than the full decarburized layer.

In the as-quenched measurement line (Fig. 1), the decarburized layer was formed in the region from 40 to $70 \mathrm{~mm}$ from the quenched end. The layer was not uniform, and there were variations in the thickness. The effect of the decarburized layer must be considered when interpreting the results from the asquenched surface for measurement locations 40-70 $\mathrm{mm}$ from the quenched end. However, for the as-quenched surface, the RMS was seen to decrease toward the end (Fig. 8b). Therefore, the effect of the soft partially decarburized layer on the BN signal was not visible in this case. In a decarburized layer, there is normally a decrease in hardness, and therefore, the RMS signal should be greater in the decarburized area. Thus, the effect of the magnetically and mechanically hard pearlite may be the primary effect influencing the RMS results.

The quenched end from the as-quenched samples had the tensile residual stresses associated with martensite transformation. It was seen in the surface images that the martensite end had undergone a volume expansion. The residual stresses were almost zero along the Jominy bar beside the quenched end. The RMS had a decreasing trend from the quenched end toward the other end with a lower cooling rate. The assumption is that the $\mathrm{BN}$ response in this case arises mainly from the microstructural effect rather than hardness because the residual stresses were equal to zero. In some studies [9, 12], a similar decreasing trend was observed with decreasing hardness, contrary to the general assumption of the RMS hardness trend. It was found that a drop in the RMS in the decreased hardness end depended on the steel grade and was also dependent on the measurement frequency $[9,12]$.

Prabhu Gaunkar et al. [15] made the same observation when they noted that the $\mathrm{BN}$ signal amplitude was higher with a martensite structure and lower for a location corresponding to a ferrite-pearlite combination. The trend in Prabhu Gaunkar et al. [15] for the BN signal amplitude was similar to that in Fig. $8 \mathrm{~b}$ for the as-quenched measurement line. However, no details were given in [15] as to whether the measurements were taken on an as-quenched surface. For the other BN parameters, Trillon et al. [13] noticed similar negative peak position values with lower hardness samples (hardness below 41 HRC). The current authors assume that Trillon et al. [13] took their measurements from the as-quenched surface. Even though similar observations were made, the interpretation of $\mathrm{BN}$ results is not a straightforward task.

It has been shown that the cooling rate has an influence on the interlamellar spacing of the pearlite structure [17]. The fine pearlite structure formed at lower temperature has been demonstrated to be much harder than the coarse pearlite formed at higher temperatures [17]. Our microhardness measurements of the pearlite-ferrite structure revealed a difference of $80-100 \mathrm{HV}_{0.005}$ in the pearlite phase hardness compared to the ferrite phase hardness (175 $\left.\mathrm{HV}_{0.005}\right)$. The pearlite hardness variations $40-70 \mathrm{~mm}$ from the quenched end were 271-283 $\mathrm{HV}_{0.005}$.

Besides the mechanical properties, Byeon and Kwun [20] concluded that the interlamellar spacing of pearlite structure influences the magnetic characteristics: coercivity and remanence as well. When the interlamellar spacing is narrower, there are more interfaces between the phases, and therefore, there is a higher probability of hindering the domain wall motion combined with higher coercivity. Nevertheless, Clapham et al. [11] stated that the interlamellar spacing has no significant effect on the signal pulse height distribution. However, it was shown in their studies that different pearlite structures produced a lot of variation in $\mathrm{BN}$ pulse heights: The higher the pearlite content, the wider the pulse height distribution. 
Clapham et al. [11] stated that $\mathrm{Fe}_{3} \mathrm{C}$ is ferromagnetic in nature, but is nevertheless considered to behave as a non-magnetic inclusion in the steel matrix. Therefore, the pearlite structure (although harder) acts as a pinning site, depending greatly on the morphology and pearlite colony direction even though the overall amount of ferromagnetic material is decreased. It is known that non-magnetic areas decrease the $\mathrm{BN}$ signal. Therefore, the decreasing RMS trend for the as-quenched measurement line may be caused by two factors: the magnetic and mechanical pinning properties of the pearlite structure caused by the lower cooling temperature and the fact that the general ferromagnetic volume is decreased. It was stated in [20] that the pearlite formed at lower temperatures achieves better mechanical properties than pearlite formed at higher temperatures. The mechanical strength is also higher when the interlamellar spacing is narrower [20].

\section{Measurements from ground surfaces}

Decreased RMS in the quenched end associated with high compressive residual stresses and increasing RMS toward the other end was observed by Franco et al. [9], who measured the $\mathrm{BN}$ from an internal ground surface. The ground surface had compressive residual stresses all along the Jominy bar caused by grinding as shown in Fig. 9a. Larger compressive residual stresses were detected in the quenched end. Our assumption is that the BN response mainly arises from a mechanically treated (ground) surface layer and is the combined result of compression generated due to grinding and microstructural change.

However, the grinding depth of the Jominy sample needs to be determined carefully. The different ground-off depth may influence the results from other sides of the Jominy bar. In this study, due to the low hardenability of the steel quality used, the martensite layer on the quenched end was shallow. Thus, the BN sensor location may be on top of two different microstructures. Persson [21] demonstrated the effect of magnetization behavior when the $\mathrm{BN}$ sensor yoke legs cover two different microstructural areas.

\section{Future considerations}

Jominy end-quench tests are relevant when developing $\mathrm{BN}$ measurement. The knowledge of what exactly what is being measured is crucial when interpreting the results. In this study, the use of two different sensors, one with pole pieces perpendicular to the ground surface and the other fitting the curved as-quenched surface, may have produced slightly different results. In the future, a certain sensor should be used that could fit both surfaces to avoid the possible effect of different sensors.

\section{Conclusions}

Jominy end-quench test samples were used for studying the relationship of microstructural changes with the magnetic Barkhausen noise response. The challenge of using these samples was that they contained all the phenomena that affect the $\mathrm{BN}$ signal and the cumulative effect of these different issues was evident. The main conclusions are:

- The ground surface showed mainly the effect of the grinding compressive stress state, while the as-quenched surface had variations due to its higher microstructure sensitivity (changes in microstructural phase, grain size, etc.). An important indication of the results was that there was variation in the sensitivity of $\mathrm{BN}$ to different surface conditions.

- The peak position value followed the hardness trend in both studied surface conditions, but the trend was more pronounced in ground surface.

- Operators that use the BN method should know which microstructural state they are measuring because the pearlite structure results may be misleading and difficult to interpret.

\section{Acknowledgements}

Jari Olavison, M.Sc., from Volvo and Turo Salomaa, M.Sc., from SSAB Europe Oy, Raahe Steelworks Laboratories, are thanked for the support and assistance in the Jominy tests. Mika Kiviluoma, B.Sc., is thanked for some of the Barkhausen noise and residual stress measurements, and Tuomas Jokiaho, M.Sc., is thanked for the SEM imaging of the samples. Financial support from the Academy of Finland is gratefully acknowledged. This work made use of the Tampere Microscopy Center facilities at Tampere University. 


\section{Author contributions}

SS contributed to conceptualization, investigation and writing, AS contributed to conceptualization, data acquisition and writing, $\mathrm{MH}$ carried out the TEM studies and their analysis, and MV supervised the study.

\section{Funding}

The research was financially supported by the Academy of Finland project.

\section{Compliance with ethical standards}

Conflict of interest The authors declare no conflict of interest.

Open Access This article is licensed under a Creative Commons Attribution 4.0 International License, which permits use, sharing, adaptation, distribution and reproduction in any medium or format, as long as you give appropriate credit to the original author(s) and the source, provide a link to the Creative Commons licence, and indicate if changes were made. The images or other third party material in this article are included in the article's Creative Commons licence, unless indicated otherwise in a credit line to the material. If material is not included in the article's Creative Commons licence and your intended use is not permitted by statutory regulation or exceeds the permitted use, you will need to obtain permission directly from the copyright holder. To view a copy of this licence, visit http://creativecommons.org/licen ses/by $/ 4.0 /$.

\section{References}

[1] SFS-EN ISO 642 (2000) Teräksen karkenevuuden määritys otsapinnan sammutuskokeen avulla (Jominykoe). SUOMEN STANDARDISOIMISLIITTO SFS

[2] Kirkaldy JS (1991) ASM handbook, volume 04-heat treating: quantitative prediction of transformation hardening in steels, United States. ASM Handbook Committee, pp 20-32. https://doi.org/10.1361/asmhba0001144

[3] Bhadeshia H, Honeycombe HR (2017) Steels: microstructure and properties, 4th edn. Elsevier, Amsterdam

[4] Cullity BD (1972) Introduction to magnetic materials. Addison-Wesley, Boston
[5] Nakah B (2017) Material characterization using Barkhausen noise analysis technique - a review. Indian J Sci Technol 10(14):1-10. https://doi.org/10.17485/ijst/2017/v10i14/ 109697

[6] Moorthy V, Vadyanathan S, Jaykumar T, Raj B (1997) Microstructural Characterisation of quenched and tempered $0.2 \%$ carbon steel using magnetic Barkhausen noise analysis. J Magn Magn Mater 171(1-2):179-189

[7] Davut K, Gür GH (2007) Monitoring the microstructural changes during tempering of quenched SAE 5140 steel by magnetic Barkhausen noise. J Nondestruct Eval 26:107-113

[8] Saquet O (1999) Barkhausen noise from plain carbon steels: analysis of the influence of microstructure. Mater Sci Eng A 269:73-82

[9] Franco F, González M, de Campos M, Padovese L (2013) Relation between magnetic Barkhausen noise and hardness for Jominy quench tests in SAE 4140 and 6150J. Nondestruct Eval 32(1):93-103. https://doi.org/10.1007/s10921-0 $12-0162-8$

[10] Lo CCH, Scruby CB, Smith GDW (2004) Dependences of magnetic Barkhausen emission and magnetoacoustic emission on the microstructure of pearlitic steel. Philos Mag 84(18):1821-1839

[11] Clapham L, Jagadish C, Atherton DL (1991) The influence of pearlite on Barkhausen noise generation in plain carbon steels. Acta Metall Mater 39(157):1555-1562

[12] Franco G, Freddy A, Padovese LR (2007) Ruido magnético de barkhausen: ensayo no destructive para la evaluación de grados de dureza en aceros. Sci Tech XIII(36):135-139

[13] Trillon A, Deneubille F, Petit S, Bisiaux B (2012) Magnetic Barkhausen noise for hardness checking on steel. 18th world conference on nondestructive testing, 16-20 April 2012, Durban, South Africa

[14] Padovese LR, Martin N, Millioz F (2009) Time-frequency and time-scale analysis of Barkhausen noise signals. In: Proceedings of IMechE v223 Part G: Journal of Aerospace Engineering, pp 577-588. https://doi.org/10.1243/0954410 0jaero436

[15] Prabhu Gaunkar NG, Nlebedim IC, Prabhu Gaunkar GV, Jiles DC (2015) Examining the correlation between microstructure and Barkhausen noise activity for ferromagnetic materials. IEEE Trans Magn 51(11):1-4. https://doi. org/10.1109/TMAG.2015.2447833

[16] SFS-EN 15305 (2008) Non-destructive testing: test method for residual stress analysis by X-ray diffraction. SUOMEN STANDARDISOIMISLIITTO SFS

[17] Schajer G (2013) Practical residual stress measurement methods. Wiley, Hoboken

[18] Miekkoja H, Lindroos V, Sulonen M, Veistinen M (1986) Uudistettu Miekkojan Metallioppi. Otava 
[19] Hao HJ, Yin W, Strangwood M, Peyton AJ, Morris PJ, Davis CJ (2010) Modelling the electromagnetic response of twophase steel microstructures. NDT\&E Int 43:305-315

[20] Byeon JW, Kwun SI (2003) Magnetic evaluation of microstructures and strength of eutectoid steel. Mater Trans 44(10):2184-2190
[21] Persson G (2018) On the modelling of a Barkhausen sensor. 12th ECNDT, 11-15 June 2018, Gothenburg, Sweden

Publisher's Note Springer Nature remains neutral with regard to jurisdictional claims in published maps and institutional affiliations. 